\title{
CONNECTING WITH DEITIES: THE PRACTICE OF SPIRIT MEDIUMSHIP AMONG THE CHINESE IN KUANTAN, PAHANG
}

\section{Melvin Foo Bok Yee* and Elena Chai}

Faculty of Social Sciences and Humanities, Universiti Malaysia Sarawak, Sarawak, MALAYSIA

*Corresponding author: melvinfby@gmail.com

Published online: 29 October 2021

To cite this article: Melvin Foo Bok Yee and Elena Chai. 2021. Connecting with deities: The practice of spirit mediumship among the Chinese in Kuantan, Pahang. Kajian Malaysia 39(2): 51-70. https://doi.org/10.21315/km2021.39.2.3

To link to this article: https://doi.org/10.21315/km2021.39.2.3

\begin{abstract}
The belief towards the spirit medium is one of the oldest beliefs in Chinese folk religion. This research explored spirit mediumship practices among the Chinese in Kuantan, Pahang, and interviewed 10 spirit mediums by applying interpretive phenomenological analysis. The findings indicate that the ability to interact with deities is either due to unavoidable illness, hereditary, naturally acquired, or learned. Indeed, a spirit medium may or may not convey messages to the audience or the deities from ritual performances. However, the ritual had revealed an "indispensable and official" status among mediums and worshippers. Although some expectations of this practice have faded due to modernity, it is still popular among the Chinese, especially in bonding the Chinese together as one community.
\end{abstract}

Keywords: Chinese folk religion, spirit mediumship, spirit medium

\section{INTRODUCTION}

According to cultural traditions, the local medium must vicariously experience three distinct stages of identity transition-pre-arrival, encounter and preservation - before getting certified as an eligible and trained medium. With such embodied knowledge as a necessary foundation, the spirit mediums have promptly received extraordinary skills and techniques of healing and divine 
prophecy for their devotees and clients. As observed, the existence of a medium office is nearly everywhere in Kuantan. The Kuantan Chinese hold that spirit mediums are specially trained personnel and gain the exact capability to serve as an intermediary between humans and gods; they are the professionals who bring the "invisible yet impossible" into life (Chan 2006; DeBernardi 2006; Lee 1986). They offer a series of services, ranging from counselling to exorcising evil spirits and soul raising. Most mediums follow the standard tradition of delivering guidance and preparing talismans or amulets while under possession by a specific deity.

As mediumship practice continues to flourish, it assembles a contrasting picture of a medium performing trance ritual, which seems to be most archaic, versus a background of a well-developed city. Such an investigation permits the realisation of the collective and cultural forces that moulded a traditional practice and remains appropriate in present-day society. Even though some approaches have evolved, the indispensable elements persist. How is the phenomenon of spirit mediumship presently in Kuantan, Pahang? What represents the practice? There are at least two plans of action in analysing these phenomena. One of them tries to discover the personality of such individuals. Questions of this attempt are likely to be, "who becomes a spirit medium and why?" The other approach discusses the social web of such individuals to find out what kind of society produces spirit mediums and where it is most likely to occur. Therefore, the research will barely pay attention to the Chinese spirit mediums in Kuantan. It is equally significant to note that this study does not neglect religious activities. Any elaboration of non-supernatural occasions will be addressed where they are relevant.

\section{Interpreting Spirit Mediums}

Accordingly, a spirit medium is subtle to the spirit realm and can interact with the entities there. Furthermore, this person is equally capable of narrating messages from the spirit world to the tangible world. To DeBernardi (2006), a medium lends their physical body to the "invisible" spiritual entities to reside in their body. Apart from that, the medium is also "a spectacle or perhaps, one might say, a miracle" (Jordan 1972, 78). The argument proposes two perceptions: in the first place, even though there might be a severe violation of the human body during possession, such as pushing skewers through their cheeks, arms, and calves, or cutting themselves in some manner, but the medium feels no pain from it; next, they are still a member of the mortal world while being possessed. 
As Bourguignon wrote, "the concept of spirit possession is dependent on the possibility of separating the self into one or more elements" $(1968,4)$. That is to say, changes in behaviour, speech, voice, facial expression, motor behaviour, appearance, and how the medium responds to others are features of the separation. Hence, the medium's altered state of consciousness is due to the presence of an external force that, or who either stimulates unusual actions or takes over the individual's personality and works within instead.

Firth applies the term "spirit mediumship" to "the use of such behavior by members of the society as a means of communication with what they understand to be entities in the spirit world" $(1967,256)$. The possessed medium must be capable of spiritual communication and interpretation. He must act under some regular and predictable speech patterns. Frazer's argument agrees with Firth's notion that the role of the medium "lies in abeyance" and every expression during the possession "are accepted as the voice of the god or spirit" (Frazer 2002, 93). As a medium, his responsibility is to communicate with the deities (Babb 1974). He offers a sense of hope in deity-medium-client relationships. In other words, "the undefined power possesses the body of a human medium and enables him to inflict injury upon himself without feeling pain and to speak with divine wisdom, giving advice to worshippers and curing their illnesses" (Elliott 1955, 15).

From the discussion above, there are two definitions of the body: the human body, the physical and real one; and the supreme body, controlled by god, and vague. The latter entails a series of demonstrations through the act of performance. In other words, the medium represents the deity himself (Stoller 2010). The concept of body in terms of how it dwells within a social space is subjective. Based on the cases concerning oneself and one's behavioural surroundings, the existence of a deity character receives a consequence in the social space. Thus, the medium as a social actor constantly regulates themselves within the transitional process to show their individuality through connections with entities from the other worlds while regularly accommodating and intervening in the separation.

\section{METHODOLOGY}

This research employs a qualitative approach to comprehend mediums' lived experiences on how spirit mediumship operates within a particular context. It is indeed a strategy to recognise the type of settings and perceive the subject's experiences-how they explain their experiences, how they experience their 
worlds, and what meaning they attach to their experiences (Merriam 2009). This approach is more concerned with the quality of experience instead of the cause-effect relationships.

An extensive revelation of the process and nature of the mediumship phenomenon, in-depth interviews and participant observations have been conducted in nearly 40 temples around Kuantan for almost 18 months, from March 2018 to September 2019. The target population includes mediums who are directly involved in the process of spirit mediumship. While this research does not centre on the occupation, educational level, marital status and ethnicity, some other conditions are to be achieved. Questions developed are based on research objectives and are provided to ask the mediums from different age groups. These sample cases have portrayed a self-sufficient and intelligible remark on the current trends and images in developing spirit mediumship in this area.

\section{CONNECTING WITH THE DEITIES}

Although they have their approaches, the medium must endure the transformation process, administering how they receive, progress and share information from the deities. On this note, therefore, this article intends to explain how the worshippers, including spirit mediums, discuss, communicate with, visualise and experience deities. With the fact that structured religious beliefs and ritual performances are relevant to the development of religious imagination, this article also explains how worshippers conceive the deities in pictures, actions and experiences.

Table 1 presents their specific demographic background and spiritual experiences. Twenty spirit mediums (mean age $=48.45$ ) from 38 Chinese temples in Kuantan took part in this study. They are all Chinese, and most of them were male (90\%), worshippers of deities, had secondary school qualifications $(45 \%)$, married $(75 \%)$, and possessed a monthly income of RM2,000 to RM3,000 $(50 \%)$.

Each of them may introduce a specific style of possession and performance. Hence, this research employs the term "Chinese style of possession" to outline how spirit mediums carry out mediumship in the community. The mediums possess Chinese deities of Buddhist origin that we commonly recognise in Mahayana Buddhism: the Mad Monk, the Baby God and those of Taoist origins 
Connecting with the Deities

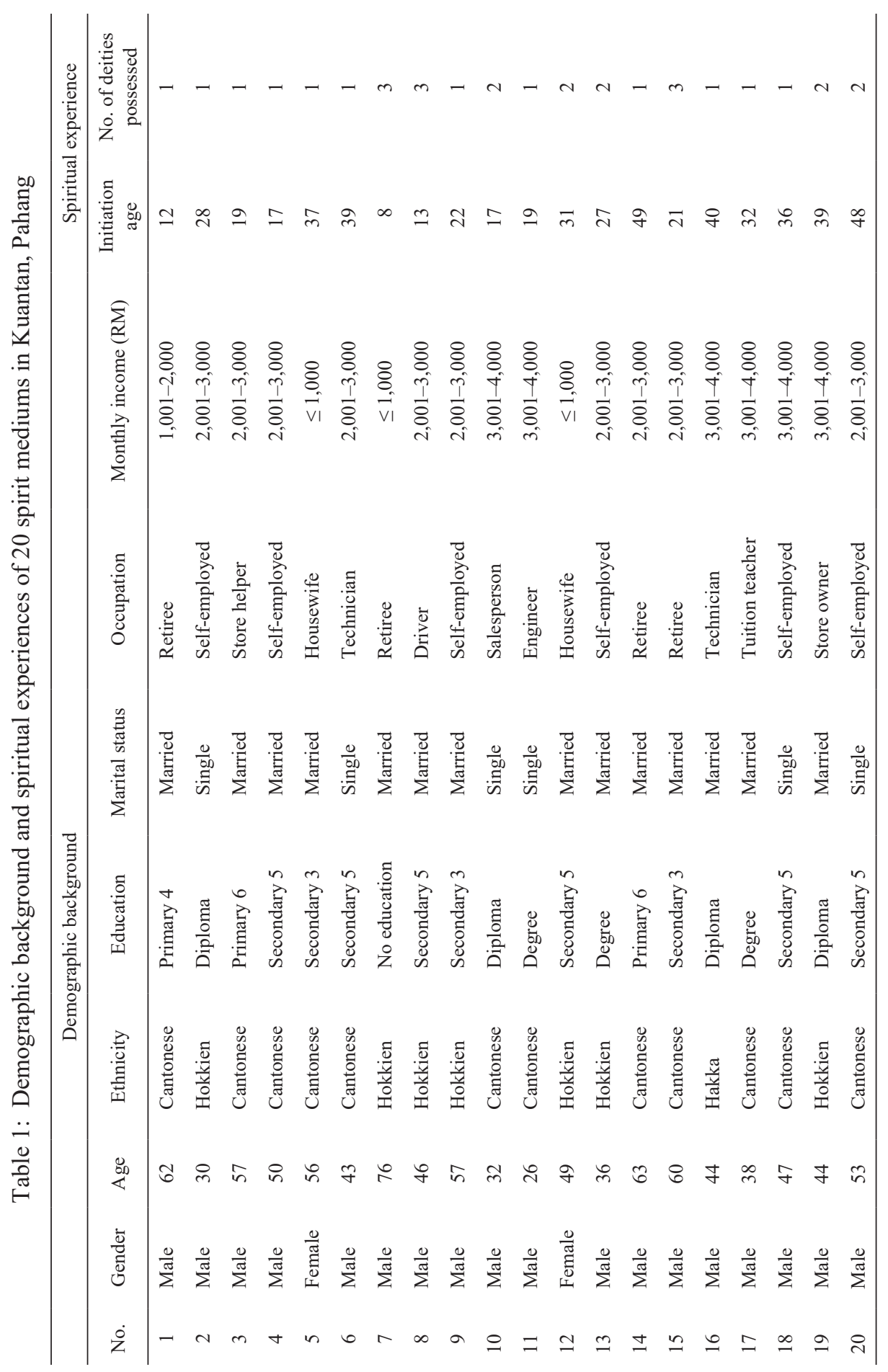


like Empress Wa, the Warrior God and the Maoshan Patriarch. This performance style exists partly due to the influence of mythology and traditional Chinese theatre. Chan (2006) mentions the worshippers how internalise deities in their memories by assimilating scenes from the dramatic yet exaggerated performance of the deities' stories replayed in the Chinese theatre. In this way, mythology became a rule or standard for Chinese mediumship practice.

In other words, mythology satisfied theatres with acting and theatres produced images of gods for the people. The spontaneous performance of the possessed medium is perceived as the exact behaviours of the deities. There endures, on this note, a debate between mythological narrations and the performances of the mediums.

\section{The Chinese Style of Possession}

In Kuantan, everyone could gain a medium status, but men dominate the practice. Regarding the correlation between the gender of spirit medium and deities, only one female medium was possessed by male deities, while the female deity possessed no male mediums. During rituals, the female medium could perform to violate cultural and social rules of appropriate female behaviour without criticism. The appearance of the opposite genders expresses the looseness between the body and the individual self. After all, they perform gender roles opposite to those of their physical bodies. For instance, case 12 is a medium of the Elder Uncle and Second Uncle. During rituals, she wears a male costume, actively consumes liquor, smokes tobacco, performs aggressive behaviours and speaks aloud. From the example, the female medium can behave like a male during rituals while these behaviours are inappropriate to her gender identity during normal times.

A standard ritual costume would differentiate a deity's identity (Figure 1). The medium's costume includes a stomacher and a ceremonial apron named the three-panel dragon's skirt. While the stomacher signifies the medium's status as a child diviner, the dragon's skirt adopts the idea from traditional Chinese theatre, in which the medium is considered a warrior. The yellow or white satin drawstring trousers, stomacher and dragon's skirt are essential elements of a medium's costume that provide ritual exposure. This assumption is satisfied by a medium that performs with his stripped body and bare feet. To such a degree, a medium is adequately dressed even if he is wearing jeans, if he is without a shirt and footwear. A female medium wears the same but over a white T-shirt due to modesty. 


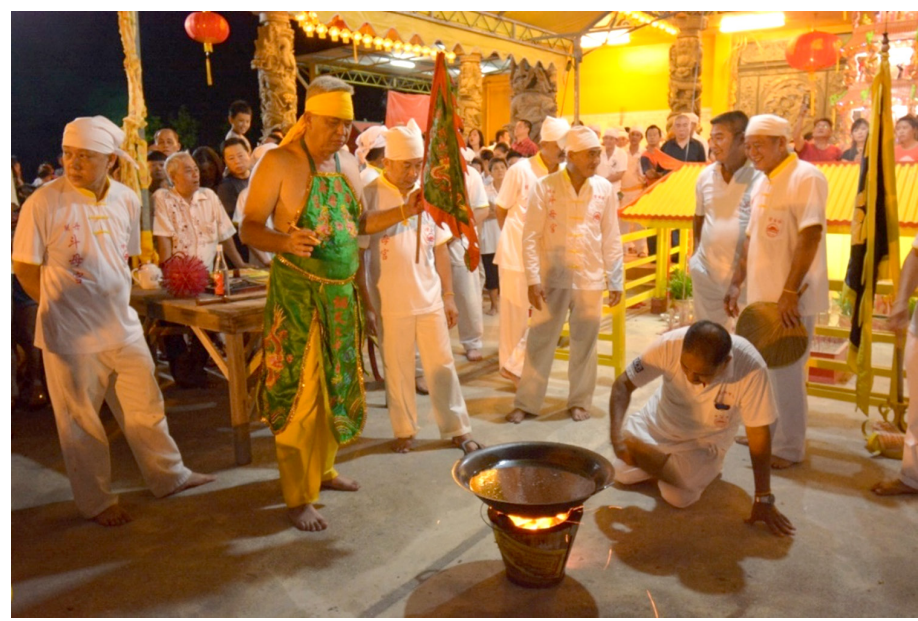

Figure 1: The medium of Warrior God wears the green stomacher and dragon's skirt while performing a ritual.

Furthermore, the colours of a medium's outfit also follow a rough code: the Warrior God wears either green or black, Empress Wa in white or pink, the Mad Monk in gray cloth that resembles the monastic, and the Elder Uncle and Second Uncle dresses in white and black, respectively. Besides, as the Baby God habitually wears red or yellow to indicate his youthful spirits, Liusheng Wangye wears yellow to manifest his power of supreme sovereignty. These selected colours represent, among other things, the five directions and the five seasons: yellow (centre and controller of the four seasons), green (east and spring), black or blue (north and winter), white (west and autumn), and red (south and summer).

\section{Conditions Initiating Possession}

From the sample of 20 cases, sickness was the most common climacteric of a person ( $40 \%$ of the cases) deciding to turn to a medium. Signs and symptoms such as severe headache, breathing difficulty, backache, anxiety without reason, irrational movements, heart or chest pain are the most popular sickness described by the mediums. These indications, in almost all cases, can hardly be alleviated using medicine in the market. Somehow, these are explained by a group of traditional healers who are mediums too. The treatment remains a form of oppression. The medium is forced to decide whether to continue to suffer or to be healed with a condition. In other words, possession remains the only way to avoid persistent sickness. After initiation, their illness will disappear at once but will recur if the deity requires them to pass a message. This group of mediums is better identified as the sick medium. 
I remembered I encountered a mysterious illness at the age of 33 . I had a terrible headache and dizziness, particularly during noontime. It was baffling to maintain my attention. I had sought my best, but everything was nevertheless out of my control. I regained no way to recover. I seek aid from alternative medical approaches, from Chinese traditional healers to specialist doctors. Unfortunately, they all came out with the same conclusion, stating I was healthy. Finally, a friend of mine suggested I visit a medium office somewhere near my house. After a few visits, the deity, Elder Uncle, a male deity, asked me to be his spokesman. As a female, I did not believe him at first. How could a male deity possess a female body? But after several rounds of negotiations, I accepted the "offer" to be his middleman. Besides that, after a few months, the Second Uncle also possessed me. (Case 12, female, 49 years old)

It was hard to maintain a family as my income became unstable after I resigned from my job. Simultaneously, I had a feeling of anxiety and confusion, and I could not control myself sometimes. Subsequently, my mother-in-law suggested my wife brought me to visit the medium. I agreed and took counsel with a medium. He informed me that Elder Uncle and Second Uncle could assist me to escape from the current situation with the request of becoming a medium. (Case 4, male, 50 years old)

Being marked by the deities is frequent. Five respondents $(25 \%)$ in the sample have come across visions or dreams preceding initiation. According to Master Hou, he was "caught" by the deity. At this point, the verb indicates the surprising way that the mediums are first possessed. This unexpected initiation repeatedly happens at temple festivals (Chan 2006; DeBernardi 2006). However, some of them, for instance, Master Seng, stated that he was forced to be a medium. This is not about learning the ability, but the ability is rewarded. This type of medium is known as the caught medium among the Kuantan Chinese.

It was a special day in my village, and that was the most prosperous year for me to join the parade. As soon as I parked my car, my body started to tremble. My hands and feet were shaking involuntarily. In an instant, my wife detected these uncontrollable movements and started to relate them to the celebration. Instead, of dispatching me to the nearest hospital, she decided to bring me to the temple for treatment. Amazingly enough, my body was just fine as usual when I was inside the temple. The medium's wife was so nervous that she could not believe I had healed. Incidentally, the parade had not yet begun. Suddenly, the medium appeared in front of me and started to examine me while reciting in Hokkien. Again, I could not control 
my body movements. It was worse this time. I could feel my saliva was dribbling out of my mouth. Someone was shouting furiously: "He's here! He's here!" (Case 19, male, 44 years old)

It was an unforgettable night. Since the exam was just around the corner, my mother brought me to a neighbouring temple to pray for a successful exam. However, it turned out with something unexpected. The moment I walked alongside the possession table, the medium yelled lustily to me. Soon enough, my body started shaking. My mom saw it and got shocked by it. Everyone tried to calm me down, but the medium told them not to do so. Less than a few minutes, I became unconscious. When I awake, they told me that I behaved like an irrepressible child, apt to do spontaneous acts like jumping here and there to give sweets, lying down to drink milk from a bottle, so on and so forth. I believed that was my first experience with Baby God. (Case 11, male, 26 years old)

By contrast, it is less familiar to provide mediums who obtained the talent from their families. Only three respondents (15\%) reported they received the skills from their parents. This talent is handed from generation to generation within the family. Individuals are encouraged to become a spirit medium as retention of family tradition. However, the ability cannot be delivered as one wishes. Preferably, the ability-transfer process must be done with a rice bowl giving ritual. As soon as they received the rice bowl, they start offering consultation services among family members. Only when their skills are mature, they will provide their services outside the family. This type of medium is recognised as the offspring of a medium.

My family produced many mediums, including me. However, I recalled nothing about spirit mediumship until I was 17 . One night, I dreamed of him (he pointed to the statue of the Warrior God). Whether from his attire or facial expression, he just looked exactly like the statue. I could not remember all that he said, except this: are you prepared? On the following day, I directly contacted my father and informed him about everything I experienced last night. Astonishingly, he smiled at me with his head nodded softly. It was so superb I had officially received the rice bowl from my father. (Case 18, male, 47 years old)

Spirit mediums who practice mediumship with personal aspirations are the learn-to-be medium who participates actively in learning and training. 
Although I learned to be a medium, I did not feel my abilities were lower than others. Someone must learn how to manage it. I was willing to learn and did put lots of effort to learn, understand, and adapt. (Case 17, male, 38 years old)

They can study from an experienced master or other mediums who once practiced mediumship or are still in service. While the other mediums are passive, they actively take the initiative and get involved with this mystical realm.

\section{THE THREE-STAGED TRANSITIONAL PROCESS}

The impact of the transitional process affects every aspect of a medium's life. Generally, the process falls into three crucial stages, namely the pre-arrival stage (conditions preceding initiation), the encounter stage (socialisation of mediumship practice) and the preservation stage (maintenance status) (Figure 2).

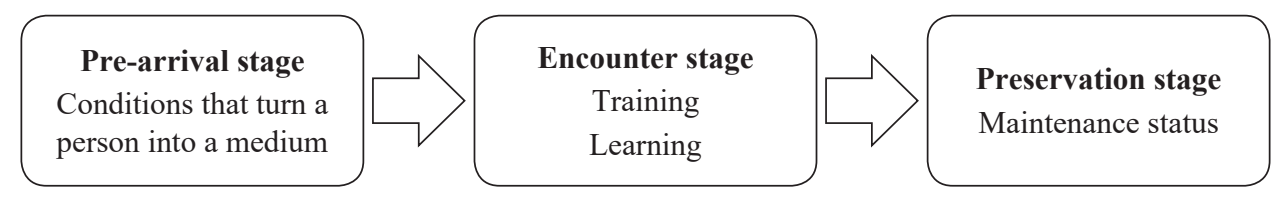

Figure 2: The three-staged transitional process of a medium.

Fistly, the pre-arrival stage concerns mainly the causes and conditions that an individual gets to be a medium. It is the prerequisite that turns or "forces" a person to become a medium. Secondly, the encounter stage includes all details of a medium's position, such as a competency-based training system involving objectives, desired end, and specific knowledge and skills that the medium will ultimately acquire for their profession. Thirdly, the preservation stage focuses on how a medium maintains the position as a medium. Undoubtedly, it is of the utmost significance for a medium to deliver satisfactory performance to uphold his status. The medium learns and accumulates experiences or conduct rituals to respond effectively to the clients' needs.

\section{The Pre-Arrival Stage}

Many individuals who face substantial competition in life and struggle for survival decide to acquire an alternative identity, a spirit medium. The turning point of becoming a medium happens at a crucial moment in their lives. While some of them encountered a varied kind of mortal and mental illness, others might suffer a downturn in life. 
These sicknesses could be untreated and remain as troubles to them. After all, their families do not hang back to bring them to the spirit medium for traditional treatment. Therefore, in a transitional phase like this, the medium found them better and gradually inspired them to enter the realm. Usually, the experienced medium, often the medium's master, associated these inescapable symptoms with the manifestations, who demanded them to remain their representatives. In unusual circumstances, the master will notify those who seek suggestions and recommendations repeatedly that if they agreed to become a medium of the deity, all these symptoms would disappear. It worked exactly like a trade-off. Hence, one can assume that this group of individuals decided to take on a new status simply because they want to escape from an embarrassing illness, as shown in cases 4 and 12 .

In addition, one's self-identification changed according to situations when the individual decided to start an alternative identity. This happened when the individual is "caught" by the deities or the family rewards the talents. At this stage, an individual, for instance, the medium of case 4 who faced a declining business, would maintain low self-esteem and confidence, and faith at all and occasionally will ask some questions in his mind such as: "Did Da Boye inquire me to be his representative or is it just my imagination?", "Did he support me in life?", "Is Da Boye truly exist?". Unlike the others, a learn-to-be medium possesses a personal desire that steers him to get involved in the learning process. In a broad sense, they believed that achieving a medium status was striving for self-fulfillment, which will improve their lives.

\section{Conditions of having divine bones and fate}

The Kuantan mediums share the ability to be possessed by deities and go into trances. The worshippers explain this gift by saying the mediums have divine bones and fairy fates. According to Potter (1974) and Chan (2006), an unborn child connects to the Heavenly Flower Gardens with 36 eternal bones. The bones work as links between the immortal soul and the mortal sphere. Ordinarily, the connections break when the child is born. However, for the medium, one bone remains. This enables the medium's soul to relinquish his mortal body during the possession, settles in the incense burner or within the Black Eight Trigram Flag, and returns to the body after the possession. The following is the excerpt from an interview with Empress Wa about the divine bone.

The divine bone is like an antenna. It connects between her and me. Because she consists of divine bone, I could assist him in improving others. It is more convenient to carry out things like this as she perceives what I want to express. (Empress Wa) 
I continue asking, "How will you choose your successor?" She replied,

Let us see. Whoever has the ability can be my successor. But it has not been found yet. The potentiality and condition have not arrived yet. It is like today. You came here to visit and end up interviewing me. It is fate. (Empress Wa)

Undoubtedly, the element of fate explains why a deity selected an individual to become a medium. The belief in fate illustrates the medium and his guardian deity have had their destiny connected. Somehow, the deity arranges the period for the medium to contribute his body to serve.

It is all about fate. If you do not have fate with the deity, even if your family draw from a medium's background, or how hard you train and learn, there is no way to be a successful medium. Otherwise, if there is fate, no matter who and where you are, He will, however, find you.

(Case 16, male, 44 years old)

\section{The Encounter Stage}

Training and learning remain two significant parts for the mediums to become accustomed to the new attitudes and a whole new pattern of behaviours. Considering this, individuals who play master and other spirit mediums are essential for regulating socialisation. They support the new medium to become familiar with attitudes, beliefs and norms to guide lifestyle transformation.

The master was notable in resolving dubious questions that occurred, for instance, why the deities selected them to be a medium or do the deities exist? In case 17, the medium learned the skills from his uncle, who was also his master at the same time. As he mentioned, his uncle instructed him on how to conduct a ritual, including inviting the deity, performing an exorcism and writing a talisman. Otherwise, the master also conveys advice about how to practice appropriately in daily life. Henceforth, the character of a master is vital in helping to socialise and build up the identity of the new medium, especially at the beginning of the process.

The new medium will also receive mediumship knowledge from other experienced mediums by asking questions or sharing personal experiences. These experienced mediums can provide alternative ways for the new mediums in solving problems. 


\section{Training subjects}

Learning style is one's way of learning. As every individual retains his or her favourite learning patterns, it is crucial to the masters and other spirit mediums to comprehend numerous styles to maximise the outcome in transferring knowledge and skills. Each new medium must know how to develop his or her attitudes and belief, the inexpressible role, and lifestyle.

To be a medium, he should adapt by taking the role of ritual assistant, establish the codes of conduct, including behavioural practices and taboos, cultivate rational beliefs and attitudes, and display a good self-image as a medium. The following are the results collected from samples.

\section{Roles as ritual assistants}

The learning medium assists the master as a ritual assistant to familiarise himself with the procedure and to gain practical experience in solving clients' problems during possession.

1. To establish the waiting order by distributing numbered cards to the clients and calling out numbers during possession.

2. To sell a packet of ritual offerings such as joss sticks, candles and paper money for praying, or a bottle of oil for putting in the lamp for meritmaking, or other ritual offerings such as fruits.

3. To explain how many incense sticks must be lit and where they must be put according to the sequences.

4. To chant a series of Chinese texts before the actual possession starts as a ritual to invite the deity.

5. To help to dress the medium when the deity has arrived.

6. To offer a cup of hot tea, or sometimes a cup of liquor to the medium or a bowl of holy water with its leafy sprinkle, and a bundle of paper packets and charms for exorcism.

7. To report the results of a pair of divining blocks; the medium will throw one on the floor for prediction.

8. To receive offerings such as a donation for the service provided, fruits, liquor, etc. 


\section{Codes of conduct}

There are some norms to obey to secure one's status as a medium.

1. To practice vegetarianism on the Buddhist holy day, the anniversaries of the patron deities, and the 1st and 15th day of every lunar month.

2. To practice the Five Precepts of Buddhism: refrain from killing, stealing, sexual misconduct, lying and consuming intoxicants.

3. Of female medium, possession rituals do not occur during the menstrual period. Menstrual blood, according to case 5, is regarded as a pollutant. Therefore, it is not a "good and pure" time for a female medium to be possessed during the menstrual period. However, this prohibition does not apply to case 12 . According to her, although a female's body is yin, the deities are male Elder Uncle and Second Uncle, and ratification was given by them so that the magic practiced is yang, and therefore ritually appropriate.

4. To enjoy an ablution to cleanse the body before any rituals.

5. The limitation of prohibited food: pork, yam, spring onion, chives, beef and lamb. In addition to the strictly forbidden food, most mediums also mentioned that they could not consume any foods or drinks at a funeral house.

Most of the mediums claimed they are restricted from attending a funeral ritual. If the medium really participated and arrived at the funeral, the ability to perform a mediumship practice would be reduced unless permission from the deity is received beforehand.

\section{Belief in merit-making}

By performing more righteous deeds, the medium is capable of obtaining a more towering achievement and, at the same time, compensating for bad karma. Some mediums also agreed that the accumulation of merits would help in purifying the mind and soul, and therefore, promote a more excellent relationship with the god or goddess. 


\section{Belief in punishment}

The concern of punishment makes clear what will occur if the medium forgets to act according to the norm-neglect to practice or obey taboos. As of carelessness, the deity will punish the medium with sickness or hardship.

Concerning the mediums' beliefs, it has been observed that most spirit mediums felt that they earned punishment from their patron deity due to their negligence to practice and follow the medium's behavioural practices and taboos. A lesson will always be given, and if they continue making mistakes, their ability to communicate with their god or goddess will be removed.

\section{Attitudes}

To maintain one's status as a spirit medium, they are expected to accept others' attitudes, including their clients and outsiders, towards their identity, particularly when others present a negative attitude towards them by condemning their practices as a deception to earn a living. Regrettably, there is nothing much that the medium could do but to acknowledge all these negative attitudes and be as careful as possible during interaction with others.

Several spirit mediums in the case studies illustrated the negative attitudes as below:

Some medium like to cheat people. If a medium demanded too much from the clients, the problem would eventually spring up. I have heard that a case near Pelindung area where a medium was involved in an accident a few years back as he deceived people by selling magical charms at an unreasonable price. Although he survived, he has received a massive injury on his left thigh. (Case 9, male, 57 years old)

There were many fake cases around. It struck those people who remained as the genuine mediums. It can be compared with one rotten egg in one egg tray, then all other eggs that belonged to the same tray are infected by the pungent smell of the rotten egg. Off and on, I was criticised by others as a false medium too. (Case 20, male, 53 years old)

From the explanation and illustration given, it should be comprehended why spirit mediums usually take precautions and worry during their meetings with others. 
These training subjects urge the new medium to practice exactly the norms and make them distinct from ordinary people. Indeed, each of them paid lots of extensive works to cultivate himself to achieve the finished state of the medium's status. It is equally important to note that both personal factors and the decision influence a complete status after gaining the status, such as his capability to compete with other mediums and improve their skills in his new lifestyle.

\section{Confirmation ritual}

After the individual has determined to undertake the duties as a spirit medium, either full-time or part-time, he must get involved in some rituals. One of them is identified as the confirmation ritual. This ritual is typically conducted by the master or a well-respected medium who is experienced in mediumship practices.

The new medium must pass a confirmation ritual to get a "license" to conduct spirit mediumships. This ritual deals mainly with the individual's ability to call or invite a god to possess their bodies. After the first time of possession, the individual will distinguish who the controller is. To develop the ritual, the teacher will invite a god to possess the new medium's body. However, before the exact ritual begins, the teacher will dispense the new medium with some advice and recommendations to follow, such as having a clear and relaxed mind, not to worry and resist during the possession, and so on. Then, upon arrival, the teacher will ask many questions to the god who inhabits the body such as, "who are you?", "what is your name?" and "what do you do?"

During the ritual, a discussion and a negotiation take place. At the end of the confirmation ritual, the master will describe the character and related details such as manners and language used by his controller to the new medium. This is because when possessed by the deity, the new medium was in a state of unconsciousness and had no memory; they hardly recall anything they did or said. For the most part, the function of the confirmation ritual or the first calling could be divided into three points.

1. To attempt, to possess and verify that the individual was possessed by a deity, or in some cases, a few deities.

2. To help the individual be assured in the presence of deities and eliminate the uncertainty about the question, "Am I possessed by god?" To put it differently, at this end, the confirmation ritual supported an individual to strengthen and recognise himself or herself as a spirit medium. 
3. To support an individual in the development and hold a medium's status because the confirmation ritual lets an individual become familiar with the character of his or her god and be prepared to construct his or her identity as a medium.

To officially become a spirit medium, the individual must receive a rice bowl from the master or patron deity. Moreover, the individual must also promise to comply with all codes of conduct to maintain a status as a spirit medium. The precepts defined in the above should be accompanied by a purification process of body, mind and soul of spirit medium since they dedicate their bodies to the deities for merit-making. In other words, they must be obliged to obey and practice the norms.

To commence the ritual, the spirit medium who is the master and the new spirit medium will enter into possession, and then the master will pass a bowlusually, a white ceramic bowl, or sometimes, a Japanese plastic bowl painted black on the outside and red on the inside - to the new medium. After the ritual, the new medium will bring the bowl to place on the altar in the living room or on the possession table. The bowl can only be handled with approval granted by the master or the guardian deity.

The rice bowl is not a bowl per se but a sense of identity and status that establishes the formal admission of an individual into a medium status. By receiving the rice bowl, they are identified as a member of the medium spirit world. It is also important to consider that on the part of the "self," the individual recognised himself or herself as a person who retains the duty as a medium to make merit by helping people in this world.

In brief, the sole purpose of receiving a rice bowl is to convert an individual from an ordinary character into a special person who acquires an outstanding ability to communicate with deities in the spiritual realm. Likewise, this ritual also reinforces one's identity as a medium. However, to be a resourceful medium, training is continued personally to be accustomed to the attitudes, beliefs and principles required to practice and obey in everyday life. These represent essential dimensions of a medium's status.

\section{The Preservation Stage}

As mentioned in the pre-arrival stage, the illness, visions, or dreams awarded by the deities, hereditary elements and personal aspirations mark the turning point that forced someone to enter the world of mediums. Then, their master, 
family members and other experienced spirit mediums were notable in influencing them to shift their meaning of self. After a certain period, when they are determined to be converted into a spirit medium, they pass a confirmation ritual and receive the rice bowl from their master or patron deity.

In this stage, the medium begins to provide their services to their family, relatives and neighbours, and if they were skillful and successful, they would accept more clients. Conversely, if he is rumoured to be deceitful, he will have no customers, and he will lose his status as a spirit medium at last. The number and viewpoints of customers and the level of self-confidence, the identity development of the new spirit medium are directly proportional. If the clients' problems are often solved, it is assumed that the medium is successful. Meantime, the new mediums will take satisfaction in their success from the evaluation of themselves. Furthermore, they believed they were valued and received appreciation from others. This situation led to a favourable attitude about themselves and bolstered them to maintain their service as a spirit medium.

As mediums are qualified and capable of communicating with the deities, they all have a prime position to free their clients from different obstacles in their life. While serving others, mediums also gain experience from practices and mistakes, which will improve their ritual performances.

Although the process of gaining a status is complex, after enrolling in spirit mediumship, they often endure the struggle to uphold their medium status. Initially, the new medium is reluctant to perform. So, often, they would also keep away from all forms of possessions and not dare to receive clients at all. Yet, they have slowly become familiar with it and dare to perform possession and receive more clients. The feeling of embarrassment is lessened and completely vanishes.

\section{CONCLUSION}

Any Chinese can be a medium. Still, to interact with the deities, he needs to obtain the necessary authority (Pregadio 2013). The relationship between men and deity, to a greater extent, is determined by the deity instead of the individual who wishes to become a medium. While hybridised identities are managed in different dialect areas, their activities are rather alike. The primary role of the spirit medium is thaumaturgical, that is, revolving around the notion of magic and miracles (Lee 1986; 1983). 
The performance of spirit mediumship is fundamentally pragmatic among the Chinese in Kuantan. Such a statement is notably absent from theoretical considerations as the social characteristics serve a multi-dimensional connection between the followers, the mediums, and the deities concerning their religious experiences and identities. At times, mediums in an altered state of consciousness, or a trance state, behave like their masters and perform assertively and skillfully with their clients. Briefly, mediums are intermediaries between the human worlds and the divinities who dwell in the spiritual realms.

However, the acknowledgement of a medium's identity is never simple. In the series of mediumship practices, a medium's body might have two levels of depiction. On the one hand, the body is objectively defined in its social and cultural aspects, while subjective elements emerge when in possession. This research revealed that a spirit medium's gender does not regularly correspond to the gender of the deities. For instance, a female medium objectively remains as a female who complies with her gender roles in everyday life. However, when a male deity inhabits her during a possession, people often neglect her gender role as a female. Rather, they decide to "re-accept" or "re-acknowledge" her as a male, furthermore, a male deity. This involves a process of construction and reconstruction of gender identity. These two levels of constructions, which often occur concurrently, also help to illustrate how people hypothesise their perceptions towards the mediums and themselves as a client.

Usually, the deity invades and controls the body of a spirit medium. They would leave their "self" to be totally converted into the deity, who constitute the source of power in conveying prophets and healing services to the client. What should not be overlooked here is that the spirit medium, most of the time a woman, is transformed into a male deity character, who presents and reveals herself through interactions with others. It is in the medium's body itself that the transformation of external power happens. This shows that the medium can accept and incorporate the external power within the subject, which is of the body, by having no fixed barriers around him or herself.

Furthermore, there are also a few notes regarding potential anticipation of one's self-transformation that could be concluded from the activities of spirit possession. Firstly, activities of spirit possession explore the hastiest and straightforward exhibitions of the imagined self. Secondly, the medium does not own a stable identity; there is no fixed barrier. They accept and attach to the external power through constant organised training, learning and experiences. 
Therefore, a medium could be transformed through ritualised actions, from woman to man, from an old man to a youthful kid, or even from the ordinary human to a powerful spiritual being.

\section{REFERENCES}

Babb, L.A. 1974. Hindu mediumship in Singapore. Southeast Asia Journal of Social Science 2(1): 229-243. https://doi.org/10.1163/080382474X00022

Bourguignon, E. 1968. A cross-cultural study of dissociational states. Columbus, OH: Research Foundation, Ohio State University.

Chan, M. 2006. Ritual is theatre, theatre is ritual: Spirit medium worship. Singapore: Wee Kim Wee Centre.

DeBernardi, J. 2006. The way that lives in the heart: Chinese popular religion and spirit mediums in Penang, Malaysia. California, CA: Standard University Press.

Elliott, A.J. 1955. Chinese spirit-medium cults in Singapore. London: Athlone Press.

Firth, R. 1967. Tikopia ritual and belief. Britain: George Allen and Unwin Ltd.

Frazer, J.G. 2002. The golden bough. Massachusetts, MA: Courier Corporation.

Jordan, D.K. 1972. Gods, ghosts, and ancestors: The folk religion of a Taiwanese village. Berkeley, LA: University of California Press.

Lee, R. 1983. Dancing with the gods: A spirit medium festival in urban Malaysia. Anthropos 78: 355-368.

. 1986. Continuity and change in Chinese spirit mediumship in urban Malaysia. Southeast Asian and Caribbean Studies 2(3): 198-214. https://doi .org/10.1163/22134379-90003355

Merriam, S.B. 2009. Qualitative research: A guide to design and implementation. New Jersey, NJ: John Wiley \& Sons.

Potter, J.M. 1974. Cantonese shamanism. In Religion and ritual in Chinese society, eds. E. Martin and A.P. Wolf, 207-232. Redwood City, CA: Stanford University Press.

Pregadio, F., ed. 2013. The encyclopedia of Taoism: 2-volume set. London: Routledge. https://doi.org/10.4324/9780203695487

Stoller, P. 2010. Fusion of the worlds: An ethnography of possession among the Songhay of Niger. Chicago, IL: University of Chicago Press. 